\title{
Novel application of PEG/SDS interaction as a wettability modifier of hydrophobic carbonate surfaces
}

\author{
Nasim Heydari ${ }^{1} \cdot$ Mahdi Asgari $^{2} \cdot$ Narjes Shojai Kaveh $^{3} \cdot$ Zahra Fakhroueian $^{2}$
}

Received: 24 April 2018/Published online: 10 October 2018

(C) The Author(s) 2018

\begin{abstract}
Wettability alteration of carbonate reservoirs from oil-wet to water-wet is an important method to increase the efficiency of oil recovery. Interaction between surfactants and polymers can enhance the effectiveness of surfactants in EOR applications. In this study, the interaction of polyethylene glycol (PEG) with an ionic surfactant, sodium dodecyl sulphate (SDS), is evaluated on an oil-wet carbonate rock surface by using contact angle measurements. The results reveal that wettability alteration of carbonate rocks is achieved through PEG/SDS interaction on the rock surface above a critical aggregation concentration (CAC). The behaviour of PEG/SDS aqueous solutions is evaluated using surface and interfacial tension measurements. Furthermore, the effect of PEG and SDS concentrations and impact of electrolyte addition on PEG/SDS interaction are investigated. It is shown that electrolyte $(\mathrm{NaCl})$ can effectively decrease the $\mathrm{CAC}$ values and accordingly initiate the wettability alteration of rocks. Moreover, in a constant SDS concentration, the addition of $\mathrm{NaCl}$ leads to a reduction in the contact angle, which can also be obtained by increasing the aging time, temperature and pre-adsorption of PEG on the rock surface.
\end{abstract}

Keywords Sodium dodecyl sulphate (SDS) · Polyethylene glycol (PEG) · Wettability alteration · Contact angle · Critical aggregation concentration $\cdot$ Carbonate surface

\section{Introduction}

The recovery of oil in naturally fractured carbonate reservoirs is low in general and can be improved significantly by the alteration of the wettability of carbonates from oil-wet conditions to water-wet conditions (Jarrahian et al. 2012; Karimi et al. 2012; Nazari Moghaddam et al. 2015). It has been found that fatty acids and carboxylates from the crude oil are strongly adsorbed onto the carbonate minerals and make the surface more oil-wet (Gomari et al. 2006; Jarrahian et al. 2012; Salehi 2009; Standnes and Austad

Edited by Yan-Hua Sun

Nasim Heydari

heydari.nasim@gmail.com

1 School of Chemical Engineering, Iran University of Science and Technology, Tehran, Iran

2 School of Chemical Engineering, College of Engineering, University of Tehran, Tehran, Iran

3 Department of Geoscience and Engineering, Delft University of Technology, Delft, The Netherlands
2000, 2003; Zhang et al. 2006). These molecules may act as "anchors" for the other polar molecules adsorbing onto the surface mostly by hydrophobic and dipole/dipole interaction in a co-operative process. Unless the injected water contains surface-active wettability-modifying chemicals, no spontaneous imbibition of water can take place under these conditions due to a negative capillary pressure (Standnes and Austad 2003).

For this purpose, chemicals such as surfactants have been widely considered before (Babadagli and Boluk 2005; Golabi et al. 2012; Hirasaki and Zhang 2004; Jarrahian et al. 2012; Kumar et al. 2016; Salehi 2009; Standnes and Austad 2000, 2003). Surfactant molecules contain at least one hydrophilic and one hydrophobic group; therefore, they can lower the interfacial tensions and alter wetting properties. SDS is one of the most popular surfactants. Due to the presence of the sulphate group, this surfactant is sensitive to temperature (Chegenizadeh et al. 2016). Thus, SDS performance is more effective in reservoirs with lower temperature. For instance, in China 13 field cases have been studied with the highest reservoir temperature of $86{ }^{\circ} \mathrm{C}$ (Olajire 2014). It has been confirmed that an anionic 
surfactant such as SDS cannot change the wetting conditions towards strongly water-wet (Jarrahian et al. 2012; Salehi 2009; Standnes and Austad 2000). As an anionic surfactant, SDS adsorption to the rock surface, through hydrophobic interaction between its tail (hydrophobic part) and the adsorbed acid molecule on the surface, changes the wettability of rock to neutral-wet condition. Among nonionic, cationic and anionic surfactants, the ability of modifying the wetting properties to more water-wet decreases in the order: cationic $>$ non-ionic $>$ anionic (Jarrahian et al. 2012; Standnes and Austad 2000). The cationic monomers interact with negatively charged adsorbed materials, mostly carboxylic groups, by electrostatic forces and desorb them from the rock surface by forming an ion pair (Gupta and Mohanty 2008; Jarrahian et al. 2012; Kumar et al. 2016; Salehi 2009; Standnes and Austad 2000). Pillai et al. (2018) investigated the ability of a series of synthetized ionic liquids to alter the wettability of an oil-wet quartz surface. Wettability alteration was achieved by ion-pair formation through the interaction between the positively charged head groups of the ionic liquid and the carboxylic acid groups from crude oil (Pillai et al. 2018). Adsorption of non-ionic surfactant on the rock surface through the polarization of $\pi$ electrons and ion exchange releases stearic acid from the surface. The acid is then adsorbed on the surface as a new layer through hydrophobic interaction between its non-polar part and the tail of the adsorbed surfactants (Jarrahian et al. 2012).

In addition, Dutkiewicz and Jakubowska (2002) have studied the influence of the type and concentration of electrolytes on the values of the critical micelle concentration (CMC) and the degree of electrolytic micelle dissociation of aqueous solutions of SDS. They found that electrolyte cations cause a decrease in the $\mathrm{CMC}$ in the order: $\mathrm{Na}^{+}<\mathrm{NH}_{4}{ }^{+}<\mathrm{K}^{+}<\mathrm{Mg}^{2+}$, and that the anions enhance the degree of electrolytic micelle dissociation in the order: $\mathrm{F}^{-}>\mathrm{ClO}_{4}{ }^{-}>\mathrm{Cl}^{-}$. $\mathrm{NaCl}$ has the minimum effect on the electrolytic micelle dissociation of SDS solution.

Surface activity of the surfactants can be increased by surfactant/polymer interaction, resulting in a reduction in interfacial tension between the oil and the injected fluid and also wettability alteration by formation of a multilayer (Karimi et al. 2012). Water-soluble polymers often interact with surfactants in aqueous solutions, and due to the importance of applications of such mixtures, there is a great interest in a better understanding of the nature of the interaction and the behaviour of polymer/surfactant mixtures in the solution as well as at the interfaces (Penfold et al. 2006; Purcell et al. 1998). For this purpose, polyethylene glycol (PEG) and sodium dodecyl sulphate (SDS) are the most studied systems. Using PEG reduces the chromatographic separation of surfactant components
(Osterloh and Jante Jr 1992). In addition, the polymer interaction with surfactant can decrease the alkalinity in ASP flooding in order to reduce the scaling problems of the rock minerals.

Polymers are susceptible to mechanical degradation at high temperatures, and this occurs at lower temperatures in the case of high salinities, and this characteristic puts certain restrictions to their use in high-temperature reservoirs. PEG has been mentioned as being water soluble, salt tolerant and in some cases, thermo-responsive. Thus, the use of PEG in the preparation of surface-active polymers has recently experienced a great interest (Raffa et al. 2016). Osterloh and Jante Jr (1992) used a high salinity brine of $190,000 \mathrm{mg} / \mathrm{L}$ TDS, to verify whether the PEG addition can improve the cost-effectiveness of surfactant/polymer flooding. da Silva et al. (2004) studied the effect of temperature in the SDS/PEG interaction within the range of 15-65 ${ }^{\circ} \mathrm{C}$ and observed that temperature variations are not so significant as to influence the intensity of the interaction of PEG with SDS. In order to determine the cloud-point curve of the solutions of PEG in $t$-butyl acetate and in water, Saeki et al. (1976) examined the thermal degradation of PEG. They confirmed that no thermal degradation was observed for a solution of PEG in water in the range of 40-240 ${ }^{\circ} \mathrm{C}$.

Jones (1967) showed that by changing SDS concentration, the surface tension behaviour falls into three distinct regions with two transition points. The first one is the point at which binding of surfactant aggregation to the polymer chain starts and often known as critical aggregation concentration (CAC). The second transition point is the critical micelle concentration (CMC). Between CAC and CMC, surface tension plots go through a plateau till all binding sites on the polymer chain are occupied and then start to fall again; this point is referred to as the polymer saturation point (PSP). It is confirmed that the surface tension at CAC is dependent on polymer concentration (Dey et al. 2015; Jones 1967); however, the surfactant concentration at this point is independent of polymer concentration (Dai and Tam 2001; Jones 1967; Moroi et al. 1977). It is worthwhile to mention that in several studies a minimum point was observed in the surface tension isotherm due to the presence of dodecanol as an impurity in the SDS used (Dey et al. 2015; Lin et al. 1999; Umlong and Ismail 2007).

It has been known that the driving force of the polymersurfactant complex formation is the interaction between anionic head groups of the surfactant aggregation and the ethylene oxide group of polymer (de Alvarenga et al. 2004), and both hydrophobic and electrostatic interactions are playing a role in the formation of the polymer-surfactant complex (Dey et al. 2015). The well-known structure for these complexes is the necklace model, in which the SDS aggregations are bound to the polymer chain like 
pearls of a collar (de Alvarenga et al. 2004; da Silva et al. 2004; Jiang and Han 2000). It has been proved that for polymers with molecular weights above 4000 , interactions between PEG and SDS in aqueous solutions are independent of the polymer molecular weight (de Alvarenga et al. 2004; da Silva et al. 2004; Maltesh and Somasundaran 1992). Using calorimetric investigation, Dai and Tam (2001) revealed that CAC is not sensitive to the molecular weight of PEG. Calorimetric investigation also showed that $1500 \mathrm{~g} / \mathrm{mol}$ is the minimum polymer molecular weight for the interactions to proceed (da Silva et al. 2004).

To the best of our knowledge, the PEG/SDS interaction has been only studied by Maltesh and Somasundaran (1992) at a water-silica interface. They observed that SDS does not interact with silica, although it adsorbs onto it in significant amounts in the presence of pre-adsorbed PEG. Also, the binding of SDS to PEG at the solid-liquid interface is stronger than the binding in the bulk solution (Maltesh and Somasundaran 1992). A well-known fact is that alkaline solutions and some surfactant solutions can change wettability towards more water-wet. However, the impact of polymer on wettability is not much discussed. Although PEG/SDS interaction in the bulk solution has been widely studied in the previous literature, little attention has been devoted to their interaction at the solid-liquid interface. The main objective of this work is to investigate the interaction mechanisms between PEG/SDS in the bulk solution and on the surface, and the effect of this interaction on the adsorption characteristics of the polymer and the surfactant at the interface of oil-wet carbonate and water. This interaction can effectively modify the wetting properties of the carbonate rock, while SDS solutions could not by themselves change the wettability to strongly waterwet $\left(\theta<50^{\circ}\right)$. Wettability alteration from oil-wet to waterwet can significantly enhance oil recovery in fractured reservoirs. We performed wettability evaluation by contact angle measurements. In addition, the PEG/SDS interaction in bulk solution was studied using surface and interfacial tension measurements. The effect of polymer concentration and molecular weight, surfactant concentration, addition of electrolyte, aging time and temperature on this interaction were also investigated.

\section{Materials and methods}

$n$-hexane (99\% purity) and $n$-decane ( $95 \%$ purity) were obtained from Merck ${ }^{\mathrm{TM}}$. These were used as the oil phase for IFT and contact angle measurements, respectively. For further purification, they were passed through an alumina column five times. In addition, crude oil from the Nowruz oil field (Iran) was obtained and used. Sodium chloride ( $\mathrm{NaCl}, 99 \%$ purity) as electrolyte, sodium dodecyl sulphate
(SDS), with a purity of $90 \%$, and polyethylene glycol (PEG) with two different molecular weights of 400 and 20,000 were also obtained from Merck ${ }^{\mathrm{TM}}$. SDS has a molecular weight of $288.38 \mathrm{~g} / \mathrm{mol}$ and a CMC concentration of $0.24 \mathrm{~g} / 100 \mathrm{~mL}$ distilled water at ambient temperature.

Wettability evaluations were conducted on carbonate rock samples provided by the Masjed Soleyman oil reservoir (Iran). The carbonate samples were first cut into small substrates, $15 \mathrm{~mm} \times 15 \mathrm{~mm}$, using a trimming machine and then were polished with an end-face grinder to achieve a flat and smooth surface. They were cleaned in a DeanStark apparatus for 7 days in contact with toluene vapour at ambient pressure. All samples were then aged in crude oil for 1 week at $80{ }^{\circ} \mathrm{C}$ and atmospheric pressure to alter the wetting tendency of the surface to nearly oil-wet. After cooling, the samples were washed with $n$-heptane and distilled water and dried at $40{ }^{\circ} \mathrm{C}$ for $24 \mathrm{~h}$ (Karimi et al. 2012). The dried samples were submerged in different PEG/SDS solutions at different temperatures for different aging times. To determine the contact angle, an $n$-decane droplet was released and captured below the rock substrate which was initially submerged in distilled water. Then, images of the droplets were taken using a microscopic camera and used as input for the image analysis to determine the contact angle.

Furthermore, surface tensions were measured by the drop weight method, and interfacial tensions were determined using the ring method by a KSV Sigma 700 tensiometer. Both measurements were taken at room temperature $\left(22{ }^{\circ} \mathrm{C} \pm 1\right)$.

\section{Results and discussion}

\subsection{Surface and interfacial tensions}

In order to compare PEG/SDS interaction in the bulk solution and at the interface of the solid/liquid, surface and interfacial tension measurements were taken. The results are shown in Figs. 1, 2, 3, 4 and 5. Surface tension results follow the same trend as previous findings (Cooke et al. 1998; Jones 1967; Müller et al. 2003; Purcell et al. 1998; Umlong and Ismail 2007); however, the previous minimum point, attributed to an SDS impurity (Dey et al. 2015; Lin et al. 1999; Umlong and Ismail 2007), has not been observed in surface tension measurements.

Figure 1 shows that CAC occurs at the SDS concentration of $0.168 \mathrm{~g} / 100 \mathrm{~mL}(0.7 \mathrm{CMC}$ of free polymer solution). This is the onset of binding of SDS micellar aggregates to PEG chains. This binding is driven by hydrophobic interactions between them (Müller et al. 2003). In the surface and interfacial tension plots, the $x$ - 


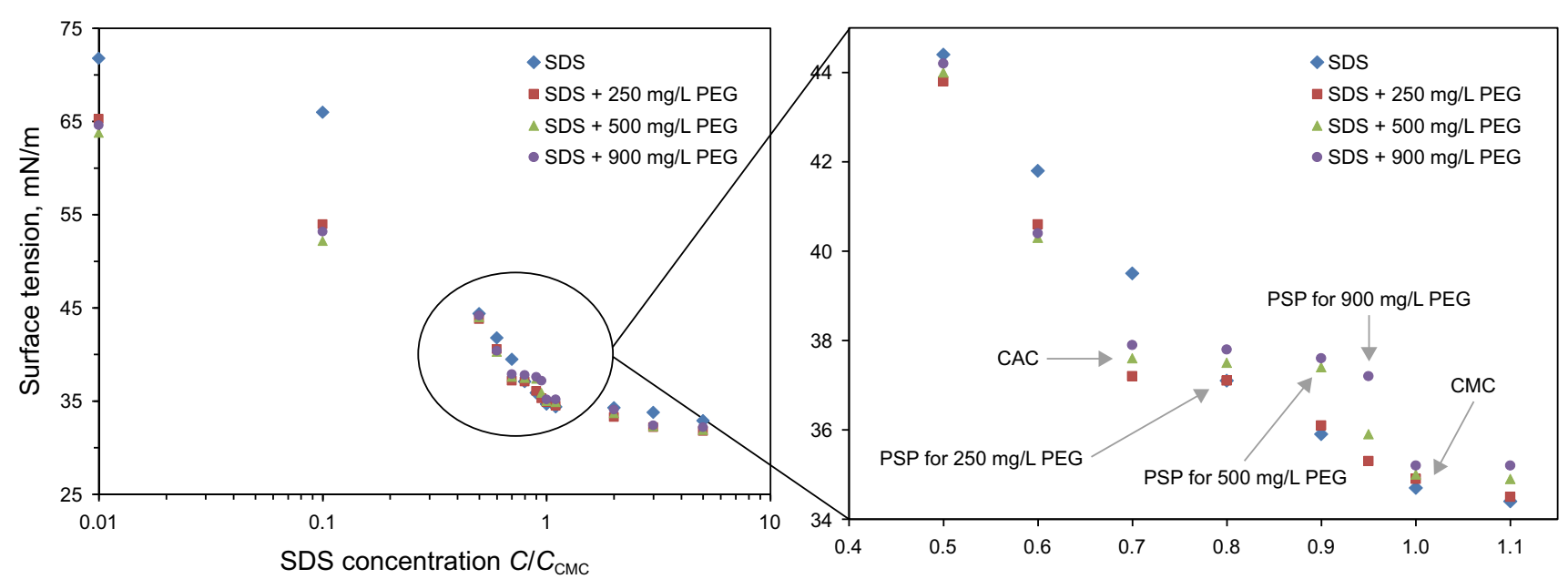

Fig. 1 Surface tension of PEG-20,000/SDS aqueous solution at various PEG concentrations

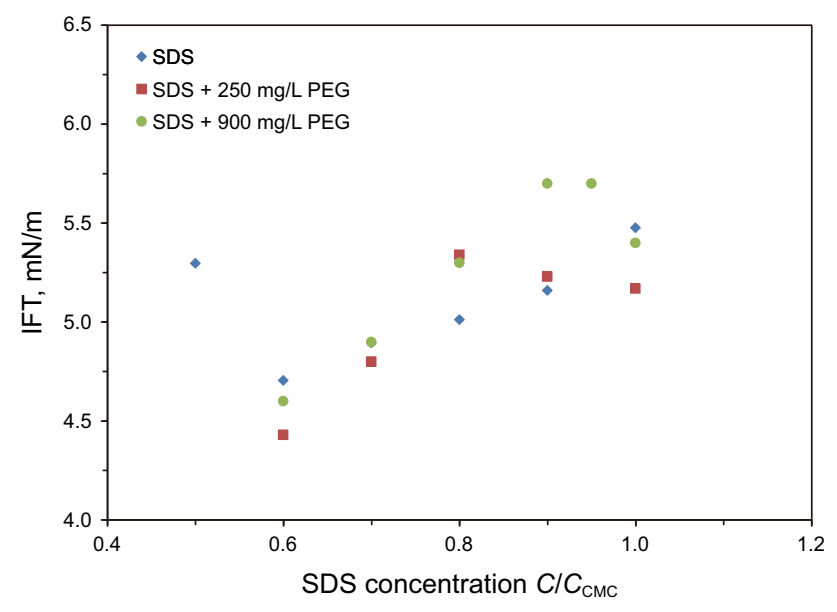

Fig. 2 Interfacial tension of $n$-hexane and PEG-20,000/SDS aqueous solutions at various PEG concentrations

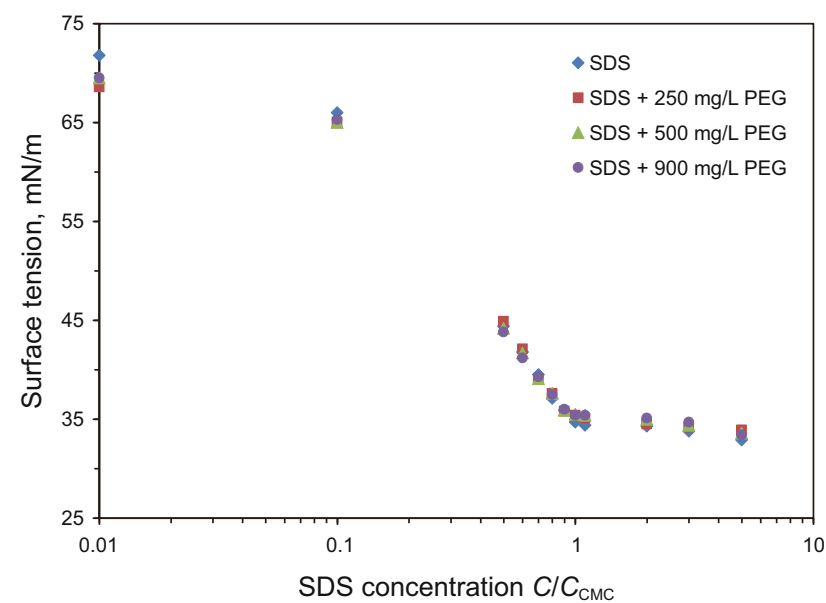

Fig. 3 Surface tension of PEG-400/SDS aqueous solution at various PEG concentrations

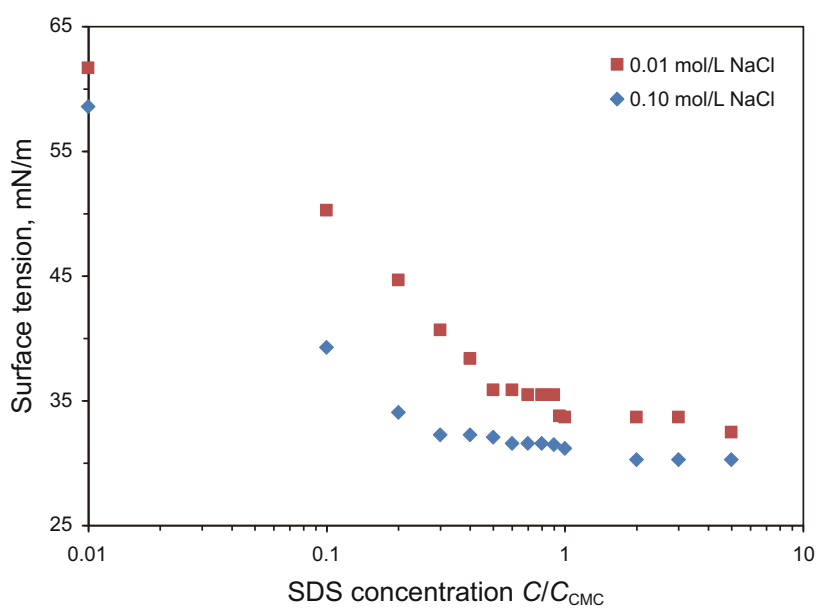

Fig. 4 Examination of $\mathrm{NaCl}$ effect on surface tension of PEG-20,000 $(900 \mathrm{mg} / \mathrm{L}) / \mathrm{SDS}$ aqueous solution

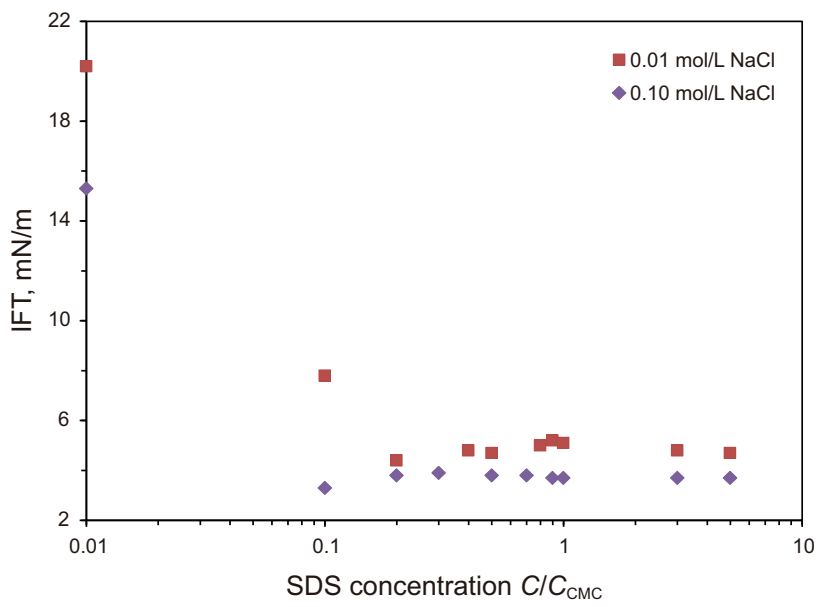

Fig. 5 Examination of $\mathrm{NaCl}$ effects on interfacial tension of $n$-hexane and PEG-20,000 (900 mg/L)/SDS solution 
axis shows the concentration of SDS in the solution divided by the CMC concentration of pure SDS aqueous solution. The maximum standard deviation in surface and interfacial tension measurements was 0.4 and 0.1 , respectively.

At SDS concentrations below the CAC, since there is no interaction between the polymer chains and the surfactant, the addition of polymer decreases the surface tension of polymer/surfactant aqueous solution due to the slight surface activity of PEG (Müller et al. 2003).

At the CAC point, the surfactant monomers form aggregations instead of being adsorbed on the surface of the solution. These formed micelles are smaller in size as well as in the number of monomers with respect to the normal micelles in CMC. These aggregations are attached and bonded to polymer chains. The aggregation forming and bonding to polymer has a similar trend to micelle formation (Jones 1967). Surface tension at the CAC point increases with increasing polymer concentration. These results are in a good agreement with the previous findings of Jones (1967).

It has been confirmed that above CAC, higher SDS concentrations lead to larger aggregations (Brown and Fundin 1992). According to Fig. 1, PSP occurred at higher SDS concentration as the polymer concentration increases, because of more binding sites. Above the PSP, surface tension again decreases until reaching the CMC.

In Fig. 2, the minimum point may be attributed to the presence of the highly surface-active lauryl alcohol (dodecyl alcohol or dodecanol) as an impurity in the SDS sample. When micelle formation starts, the impurity becomes dissolved in the micelles because of its hydrophobic nature. This lowers the concentration of lauryl alcohol in the bulk and hence its surface concentration. Consequently, the interfacial tension increases and returns to that of pure SDS solution (Dey et al. 2015; Lin et al. 1999; Umlong and Ismail 2007). It is possible that small aggregates (pre-micelles) build up below the CAC and $\mathrm{CMC}$, starting at a concentration with a minimum surface tension (Lin et al. 1999). By start of the pre-micelle formation, IFT increases till the PSP is reached in surface tension plots $(0.8$ and $0.95 \mathrm{CMC}$ for 250 and $900 \mathrm{mg} / \mathrm{L}$, respectively); then, it decreases till the CMC point. It was expected that by saturation of the polymer chain, the concentration of SDS monomers would increase again at the water $n$-hexane interface.

Surface tension measurements were also conducted for PEG-400/SDS aqueous solutions, and results are shown in Fig. 3. No break points were observed in the surface tension plots, and they show similar trends to polymer-free solution. There is no interaction observed between PEG400 and SDS in the bulk solution. The results are in a good agreement with previous findings (da Silva et al. 2004; Dey et al. 2015). Using isothermal titration calorimetry (ITC),
Dai and Tam (2001) found that the binding behaviour of PEG and SDS in the bulk solution is dependent on the molecular weights of PEG. When the molecular weight of PEG is low, such as with the molecular weight of 400 , the hydrophilic nature of the polymer chain dominates and no interaction with SDS occurs (Dai and Tam 2001).

In Fig. 4, variation of surface tension of PEG-20,000/ $\mathrm{SDS}$ aqueous solution in the presence of $\mathrm{NaCl}$ is presented when the concentration of PEG is $900 \mathrm{mg} / \mathrm{L}$. Addition of $\mathrm{NaCl}$ led to lower surface tension in the same SDS concentrations, which is an important application for EOR. Electrolytes decrease the surface tension of the solutions, and its role is more obvious in SDS concentrations less than the CAC. For instance, the surface tension in the solution of $0.1 \mathrm{CMC}$ of SDS was $66.0 \mathrm{mN} / \mathrm{m}$ and by adding $900 \mathrm{mg} / \mathrm{L}$ of PEG-20,000, it decreased to $53.2 \mathrm{mN} / \mathrm{m}$, while the surface tension decreased to the value of 50.3 and $30.3 \mathrm{mN} / \mathrm{m}$ by adding 0.01 and $0.1 \mathrm{~mol} / \mathrm{L} \mathrm{NaCl}$, respectively. Due to the counterion effects, electrolytes can force more surfactant molecules to diffuse from the bulk solution to the surface resulting in surface tension reduction (Kumar et al. 2016; Umlong and Ismail 2007).

In Fig. 4, CAC occurred at an SDS concentration of 0.5 CMC (0. $12 \mathrm{~g} / 100 \mathrm{~mL})$ and $0.3 \mathrm{CMC}(0.072 \mathrm{~g} / 100 \mathrm{~mL})$ in the case of solutions containing 0.01 and $0.1 \mathrm{~mol} / \mathrm{L} \mathrm{NaCl}$, respectively, both of which are lower than the $\mathrm{CAC}$ in solution without $\mathrm{NaCl}$. Thus, it can be concluded that $\mathrm{NaCl}$ facilitates the formation of SDS aggregates due to ionic screening of the counterions (Dutkiewicz and Jakubowska 2002; Umlong and Ismail 2007). In the presence of electrolyte, less SDS monomers are needed to form an aggregate, so active sites on the polymer chain are occupied with lower SDS concentration. Consequently CAC, PSP and CMC are shifted to the lower SDS concentration.

In Fig. 5, the data of interfacial tension of $n$-hexane and PEG-20,000 (900 $\mathrm{mg} / \mathrm{L}) / \mathrm{SDS}$ solution in the presence of $\mathrm{NaCl}$ are presented. Accordingly, the minimum point in the IFT curves shifted to 0.1 and $0.4 \mathrm{CMC}$ in the case of 0.1 and $0.01 \mathrm{~mol} / \mathrm{L} \mathrm{NaCl}$, respectively. In the solution containing $0.01 \mathrm{~mol} / \mathrm{L} \mathrm{NaCl}$, IFT increased till the SDS concentration of $0.9 \mathrm{CMC}$ and afterwards it remained almost constant. In the solution containing $0.1 \mathrm{~mol} / \mathrm{L} \mathrm{NaCl}$, after the minimum point at $0.1 \mathrm{CMC}$, IFT increased till an SDS concentration of $0.3 \mathrm{CMC}$, which was assumed as the CAC in surface tension measurements. Subsequently, with the addition of further SDS, IFT remained almost unchanged. These observations are in good agreement with the surface tension results shown in Fig. 4.

\subsection{Contact angle}

To study the interaction of PEG/SDS on an oil-wet carbonate surface, contact angle measurements were taken. 
Initially, the substrates were aged in the crude oil for 1 week at $80^{\circ} \mathrm{C}$ and atmospheric pressure which made them strongly oil-wet. To investigate the effect of aging time, samples were aged in different PEG/SDS solutions for 24 and $72 \mathrm{~h}$ at atmospheric conditions. The results are summarized in Table 1 . To check the repeatability of the experiments, 10 random aqueous solutions of SDS/PEG were chosen and two rock samples were submerged in each solution for $24 \mathrm{~h}$ at room temperature. Then, contact angle measurements were taken for both substrates. The maximum difference between two repeated tests was 8 degrees.

The results in Table 1 show that the treatment of SDS aqueous solutions did not change the wettability of the rocks to water-wet even after $72 \mathrm{~h}$ of aging with SDS concentration of $1.2 \mathrm{~g} / 100 \mathrm{ml}$ (5 CMC). This is mainly due to the fact that anionic surfactants are not able to desorb anionic organic carboxylates from the rock surface in an irreversible way. This observation is in good agreement with the previous findings in the literature (Jarrahian et al. 2012; Standnes and Austad 2000).

However, the presence of PEG in surfactant solutions, with molecular weights of 400 and 20,000, is able to change the wettability of carbonate samples from oil-wet to water-wet, effectively above the CAC of the surfactant (obtained from surface tension measurements in Fig. 1). Therefore, it can be concluded that PEG/SDS interaction plays a considerable role in wettability alteration of carbonate surfaces. PEG/SDS complexes can be adsorbed on the rock surface through the PEG non-ionic chain. These complexes form an ionic layer on the rock surface which is hydrophilic, because of SDS aggregations. Consequently, the wettability of rocks alters to water-wet through multilayer formation on the surface. In fact, PEG has an intermediate role for SDS adsorption on the rock surface. The similar contact angles achieved through different molecular weights of PEG can be explained by the similar amount of SDS binding with the adsorbed polymer on the surface. A similar observation has been made by Maltesh and Somasundaran (1992) measuring the amount of SDS binding with PEG. There was no measurable effect of molecular weight of the PEG on the amount of SDS extracted from the solution onto the silica-water interface (Maltesh and Somasundaran 1992).

Figure 6 demonstrates the PEG/SDS interaction at different concentrations of SDS and shows how the wettability alteration of carbonates is achieved through the ionic layer formation of SDS/PEG complex.

However, the results presented in Fig. 3 confirm that PEG 400 did not interact with SDS in the bulk solution. Their interaction on the carbonate surface is only observed through contact angle measurements, which can be explained by the stronger interaction between PEG/SDS at a solid-liquid interface. Similar observations have been made by Maltesh and Somasundaran (1992) investigating on the amount of SDS adsorption to PEG in the bulk solution and on the surface. The adsorption ratio of SDS to ethylene oxide was 0.671 , which was higher than the ratios reported for bulk interactions between PEG and SDS by Shirahama (0.4142) (Shirahama 1974) and by Francois et al. (0.38) (Francois et al. 1985). It was suggested that the interaction between PEG and SDS is stronger at the solidliquid interface than that in the bulk solution. Using spectroscopic techniques, they reported that the surfactant aggregations formed at the solid-liquid interface are more tightly packed than surfactant micelles formed in the bulk solution. Similarly, SDS bound to PEG at the solid-liquid

Table 1 Results of contact angle measurements after aging in different PEG/SDS solutions

\begin{tabular}{|c|c|c|c|c|c|c|c|}
\hline \multirow{3}{*}{$\begin{array}{l}\text { Aging time, } h \\
24\end{array}$} & \multirow{3}{*}{$\begin{array}{l}\begin{array}{l}\text { Molecular } \\
\text { weight of PEG }\end{array} \\
400\end{array}$} & \multirow{3}{*}{$\begin{array}{l}\text { SDS concentration } \\
C / C_{\mathrm{CMC}} \\
0.1\end{array}$} & \multicolumn{5}{|c|}{ Contact angle, degree } \\
\hline & & & \multirow{2}{*}{$\begin{array}{l}\text { Polymer-free } \\
158\end{array}$} & \multicolumn{2}{|c|}{$250 \mathrm{mg} / \mathrm{L}$ PEG } & \multicolumn{2}{|c|}{$900 \mathrm{mg} / \mathrm{L}$ PEG } \\
\hline & & & & 145 & 144 & 143 & 148 \\
\hline & & 0.5 & 144 & 135 & 132 & 129 & 125 \\
\hline & & 0.7 (CAC) & - & 59 & 55 & 56 & 55 \\
\hline & & 1.0 & 136 & 57 & 53 & 55 & 53 \\
\hline & & 3.0 & 128 & 53 & 45 & 56 & 49 \\
\hline & & 5.0 & 122 & 54 & 45 & 53 & 49 \\
\hline \multirow[t]{6}{*}{72} & 20,000 & 0.1 & 153 & 142 & 137 & 133 & 132 \\
\hline & & 0.5 & 143 & 130 & 124 & 124 & 115 \\
\hline & & 0.7 (CAC) & - & 56 & 55 & 50 & 52 \\
\hline & & 1.0 & 132 & 56 & 50 & 48 & 45 \\
\hline & & 3.0 & 127 & 51 & 45 & 47 & 43 \\
\hline & & 5.0 & 120 & 50 & 43 & 48 & 41 \\
\hline
\end{tabular}




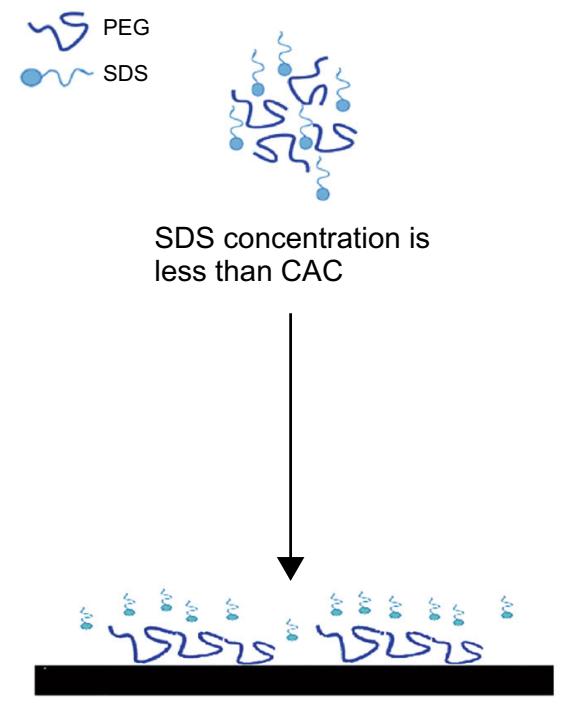

SDS monomers couldn't be adsorbed on the oil-wet carbonate surfaces due to the same negative charges

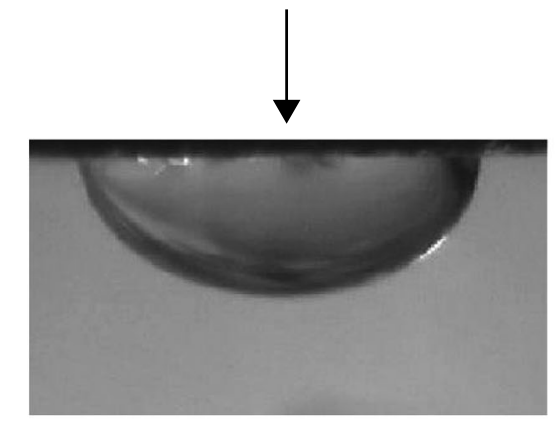

Wettability alteration of carbonate surface from oil-wet to water-wet cannot be achieved.

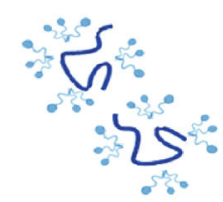

SDS concentration is equal to $C A C$
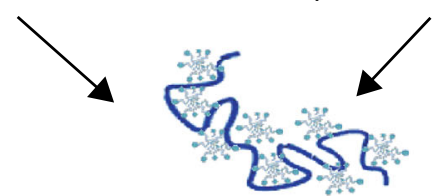

Necklace model of

SDS/PEG complex

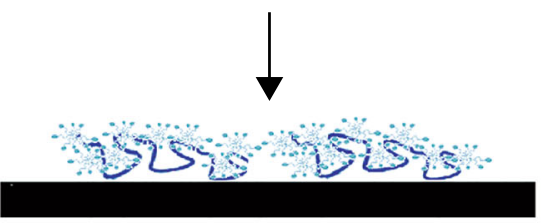

An ionic layer is formed on the oil-wet carbonate surfaces through multilayer formation

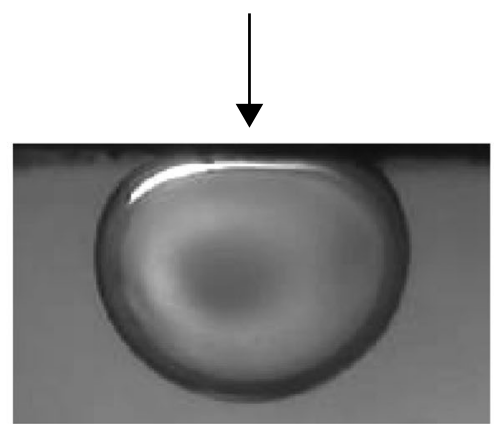

Wettability alteration of carbonate surface from oil-wet to water-wet is achieved.

Fig. 6 Schematic of SDS/PEG interaction on a carbonate surface at different SDS concentration regions to alter the wettability

interface could be more tightly packed than the SDS bound to PEG in the bulk solution, accounting for the high binding ratio of SDS to PEG. They also suggested that the mechanism of interaction between SDS and PEG at the surface could be similar to that in the bulk solution, which can be attributed to the association between the ether oxygen of the polymer and the head group of the surfactant aggregations (Maltesh and Somasundaran 1992). This can also explain the observations on the oil-wet carbonate surfaces.

Moreover, according to results presented in Table 1, above the CAC point, the contact angle slightly decreased with SDS concentration, polymer molecular weight, PEG concentration and aging time. By adding more SDS, more aggregations could be adsorbed to polymer chains, and by increasing the PEG concentration, more binding sites are available. In addition, SDS aggregations interact more with polymer chains by increasing the molecular weight of polymer. Furthermore, longer aging time slightly decreased the contact angle value.

In order to investigate the effect of electrolyte and temperature on interaction of PEG/SDS on the rock surface, two concentrations of $\mathrm{NaCl}$, i.e. 0.01 and $0.1 \mathrm{~mol} / \mathrm{L}$, were selected, and the samples were aged for $72 \mathrm{~h}$ in PEG20,000/SDS solutions at two different temperatures of $70{ }^{\circ} \mathrm{C}$ and $22{ }^{\circ} \mathrm{C}$. These two levels of salinity were selected based on the previous findings in the literature (Torres et al. 2008; Müller et al. 2003). Müller et al. (2003) have found that $0.1 \mathrm{~mol} / \mathrm{L}$ is a relatively high concentration to observe the aggregation behaviour in the mixture of SDS/PEG. Therefore, $0.1 \mathrm{~mol} / \mathrm{L} \mathrm{NaCl}$ was considered here as the maximum $\mathrm{NaCl}$ concentration. The tests were also 
Table 2 Effect of electrolyte and aging temperature on contact angles

\begin{tabular}{|c|c|c|c|c|c|c|}
\hline \multirow{3}{*}{ SDS concentration $C / C_{\mathrm{CMC}}$} & \multicolumn{6}{|c|}{ Contact angle, degree } \\
\hline & \multicolumn{2}{|c|}{ Salt-free } & \multicolumn{2}{|c|}{$0.01 \mathrm{~mol} / \mathrm{L} \mathrm{NaCl}$} & \multicolumn{2}{|c|}{$0.10 \mathrm{~mol} / \mathrm{L} \mathrm{NaCl}$} \\
\hline & $22{ }^{\circ} \mathrm{C}$ & $70^{\circ} \mathrm{C}$ & $22{ }^{\circ} \mathrm{C}$ & $70^{\circ} \mathrm{C}$ & $22{ }^{\circ} \mathrm{C}$ & $70^{\circ} \mathrm{C}$ \\
\hline 0.1 & 132 & 110 & 144 & 110 & 135 & 107 \\
\hline 0.3 & - & - & 120 & 102 & 117 & 90 \\
\hline 0.4 & - & - & 107 & 89 & 94 & 86 \\
\hline 0.5 & 115 & 103 & 85 & 60 & 53 & 50 \\
\hline 0.6 & - & - & 50 & 47 & 50 & 45 \\
\hline 0.7 & 52 & 52 & 49 & 47 & 43 & 43 \\
\hline 1.0 & 45 & 42 & 43 & 40 & 41 & 36 \\
\hline 5.0 & 41 & 37 & 38 & 32 & 36 & 30 \\
\hline
\end{tabular}

conducted without $\mathrm{NaCl}$ and with $0.01 \mathrm{~mol} / \mathrm{L} \mathrm{NaCl}$ as a low concentration to see the effect of adding electrolyte in small quantities. The results are presented in Table 2. PEG concentration and molecular weight were $900 \mathrm{mg} / \mathrm{L}$ and $20,000 \mathrm{mg} / \mathrm{L}$, respectively.

It was mentioned before that wettability alteration has been achieved by SDS concentrations above CAC. Based on surface tension measurements (Fig. 3), CAC was at 0.5 and $0.3 \mathrm{CMC}$ for solutions containing 0.01 and $0.1 \mathrm{~mol} / \mathrm{L}$ $\mathrm{NaCl}$, respectively. However, according to the contact angle data, water-wet condition was achieved at 0.6 and 0.5 $\mathrm{CMC}$ in 0.01 and $0.1 \mathrm{~mol} / \mathrm{L} \mathrm{NaCl}$ solutions. This difference can be attributed to the low SDS concentration at $\mathrm{CAC}$ in the presence of $\mathrm{NaCl}$. This leads to small aggregations in size and number and consequently a low density of them on the rock surface, which is not sufficient to alter the wettability. In the presence of $\mathrm{NaCl}$, contact angles are generally lower compared with the salt-free solutions at the same SDS concentrations. This may be explained by the higher intensity of SDS micelles on PEG chains, which makes the rock surface more hydrophilic. Brown and Fundin (1992) used fluorescence decay and found that at the polymer saturation point (PSP), there is a distance of approximately $90 \AA$ between adjacent micelles in salt-free solution and about $60 \AA$ at $0.8 \mathrm{~mol} / \mathrm{L}$ salt.

According to results given in Table 2, the contact angle decreased with an increase in the aging temperature. It has been reported that the PEG solubility decreases with an increase in the aging temperature. This normally results in the formation of an aqueous biphasic system, because of dehydration caused by temperature rise (Mansur et al. 2001). It leads to more adsorption of PEG on the rock surface and consequently the presence of more SDS on the surface. Anderson (1986) proved that the temperature rise can change the solubility of the wettability-altering components and desorb them from the rock surface, thus making the surface more water-wet. Adsorption of naphthenic acids and other carboxylate acids is a chemisorption reaction, which depends on temperature. Furthermore, the amount of active $\mathrm{Ca}^{2+}$ on the rock surface decreases with temperature rise (Hamouda and Rezaei Gomari 2006).

In this study, wettability alteration is also investigated with pre-adsorbed PEG on the oil-wet rock surface. To achieve this aim, the rock samples had been initially aged in the PEG-20,000 solution of $900 \mathrm{mg} / \mathrm{L}$ for $48 \mathrm{~h}$ at $70{ }^{\circ} \mathrm{C}$; afterwards, they have been aged in SDS solution for $48 \mathrm{~h}$ at $70{ }^{\circ} \mathrm{C}$. Results are presented in Fig. 7, which are compared with the contact angles of $n$-decane on the rocks aged in PEG/SDS solutions for $72 \mathrm{~h}$ at $70{ }^{\circ} \mathrm{C}$.

According to the results shown in Fig. 7, pre-adsorption of PEG on the rock surface makes them more water-wet in comparison with the rock samples aged in PEG/SDS solutions. SDS aggregations might be adsorbed to the polymer chain more tightly when it is pre-adsorbed on the rock surface. This finding is in good agreement with the observation of Maltesh and Somasundaran (1992), who reported that more SDS bonded to the pre-adsorbed PEG on the silica surface and the interaction was stronger than in the bulk solution.

\section{Conclusions}

Wettability alteration of reservoir rock from oil-wet to water-wet has a great impact on the ultimate oil recovery from fractured carbonate reservoirs. For this purpose, surfactants are widely used as wettability modifier agents. Interaction between surfactants and other chemicals such as polymers can enhance the effectiveness of surfactants in EOR application. There has recently been a great interest in PEG in this field due to its tolerance in high salinity condition.

Although PEG/SDS interaction in the bulk solution has been widely studied previously, little attention has been devoted to their interaction at the solid-liquid interface and the controlling parameters. In this study, the interaction of 


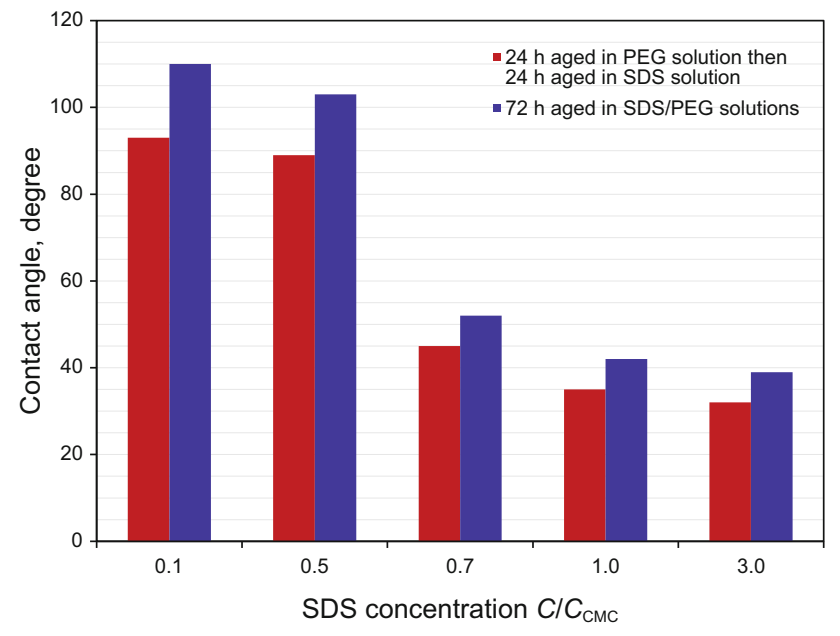

Fig. 7 Comparison of contact angles of samples aged separately in pure SDS and PEG solutions with the substrates aged in PEG/SDS solutions

PEG with SDS ionic surfactant is considered on the oil-wet carbonate rock surface as well as in the bulk solution. The results reveal that:

- PEG (400 and 20,000)/SDS interaction above CAC can alter the wettability of the oil-wet carbonate samples to strongly water-wet $\left(\theta<50^{\circ}\right)$. Wettability is an important factor in oil production increase and displacement efficiency.

- Above CAC, contact angle values reduce when the polymer concentration and the molecular weight increase. Increasing the SDS concentration significantly reduces the contact angle at SDS concentrations lower than CAC. However, above CAC, the addition of surfactant leads to only a slight change in the contact angle. In addition, increasing the aging time and temperature does not significantly reduce the contact angle.

- Addition of $\mathrm{NaCl}$ helps to form the SDS aggregations at lower SDS concentrations, which decreases CAC. As a result, wettability alteration is achieved at lower SDS concentration in the presence of electrolyte. At a constant SDS and polymer concentration, the presence of electrolyte decreases the contact angle, surface and interfacial tensions. The effect of $\mathrm{NaCl}$ is more significant at SDS concentrations lower than CAC.

- Carbonates, which have been pre-adsorbed in PEG and then aged in SDS solutions, have smaller contact angles with respect to those were aged in the combined PEG/ SDS solution with similar concentrations. This indicates that more SDS aggregations bond to the carbonate surface through pre-adsorbed PEG.
Open Access This article is distributed under the terms of the Creative Commons Attribution 4.0 International License (http://creative commons.org/licenses/by/4.0/), which permits unrestricted use, distribution, and reproduction in any medium, provided you give appropriate credit to the original author(s) and the source, provide a link to the Creative Commons license, and indicate if changes were made.

\section{References}

Anderson WG. Wettability literature survey-Part 1: rock/oil/brine interactions and the effects of core handling on wettability. Pet Technol. 1986;38(10):1125-44. https://doi.org/10.2118/13932PA.

Babadagli T, Boluk Y. Oil recovery performances of surfactant solutions by capillary imbibition. Colloid Interface Sci. 2005;282(1):162-75. https://doi.org/10.1016/j.jcis.2004.08.149.

Brown W, Fundin J. Miguel MdG. Poly (ethylene oxide)-sodium dodecyl sulfate interactions studied using static and dynamic light scattering. Macromolecules. 1992;25(26):7192-8. https:// doi.org/10.1021/ma00052a019.

Chegenizadeh N, Saeedi A, Quan X. Most common surfactants employed in chemical enhanced oil recovery. Petroleum. 2016;3(2):197-211. https://doi.org/10.1016/j.petlm.2016.11.007.

Cooke DJ, Dong CC, Lu JR, Thomas RK. Interaction between poly (ethylene oxide) and sodium dodecyl sulfate studied by neutron reflection. Phys Chem B. 1998;102(25):4912-7. https://doi.org/ 10.1021/jp9804291.

da Silva RC, Loh W, Olofsson G. Calorimetric investigation of temperature effect on the interaction between poly (ethylene oxide) and sodium dodecylsulfate in water. Thermochim Acta. 2004;417(2):295-300. https://doi.org/10.1016/j.tca.2003.07.025.

Dai S, Tam K. Isothermal titration calorimetry studies of binding interactions between polyethylene glycol and ionic surfactants. Phys. Chem. B. 2001;105(44):10759-63. https://doi.org/10. 1021/jp0110354.

de Alvarenga ES, Lima CF, Denadai ÂM. Study of aqueous solution of sodiumdodecylsulfate and polyethyleneoxide 10000 by NMR NOESY. Zeitschrift für Naturforschung A. 2004;59(4-5):291-4. https://doi.org/10.1515/zna-2004-4-515.

Dey J, Sultana N, Kumar S, Aswal VK, Choudhury S, Ismail K. Controlling the aggregation of sodium dodecylsulphate in aqueous poly (ethylene glycol) solutions. RSC Adv. 2015;5(91):74744-52. https://doi.org/10.1039/C5RA13096D.

Dutkiewicz E, Jakubowska A. Effect of electrolytes on the physicochemical behaviour of sodium dodecyl sulphate micelles. Colloid Polym Sci. 2002;280(11):1009-14. https://doi.org/10. 1007/s00396-002-0723-y.

Francois J, Dayantis J, Sabbadin J. Hydrodynamical behaviour of the poly (ethylene oxide)-sodium dodecylsulphate complex. Eur Polymer J. 1985;21(2):165-74.

Golabi E, Seyedeyn-Azad F, Ayatollahi SS, Hosseini S, Dastanian M. Experimental study of anionic and cationic surfactants effects on reduce of IFT and wettability alteration in carbonate rock. Int J Sci Eng Res. 2012;3(7):1-8.

Gomari KR, Denoyel R, Hamouda A. Wettability of calcite and mica modified by different long-chain fatty acids (C 18 acids). Colloid Interface Sci. 2006;297(2):470-9. https://doi.org/10.1016/j.jcis. 2005.11.036.

Gupta R, Mohanty KK. Wettability alteration of fractured carbonate reservoirs. In: SPE/DOE symposium on improved oil recovery, April 19-23, Tulsa, Oklahoma, 2008. https://doi.org/10.2118/ 113407-MS 
Hamouda AA, Rezaei Gomari KA. Influence of temperature on wettability alteration of carbonate reservoirs. In: SPE/DOE symposium on improved oil recovery, April 22-26, Tulsa, Oklahoma, 2006. https://doi.org/10.2118/99848-MS.

Hirasaki G, Zhang DL. Surface chemistry of oil recovery from fractured, oil-wet, carbonate formations. SPE J. 2004;9(02):151-62. https://doi.org/10.2118/88365-PA.

Jarrahian K, Seiedi O, Sheykhan M, Sefti MV, Ayatollahi S. Wettability alteration of carbonate rocks by surfactants: a mechanistic study. Colloids Surf A. 2012;410:1-10. https://doi. org/10.1016/j.colsurfa.2012.06.007.

Jiang W, Han S. Viscosity of nonionic polymer/anionic surfactant complexes in water. Colloid Interface Sci. 2000;229(1):1-5. https://doi.org/10.1006/jcis.2000.6971.

Jones MN. The interaction of sodium dodecyl sulfate with polyethylene oxide. Colloid Interface Sci. 1967;23(1):36-42. https://doi.org/10.1016/0021-9797(67)90082-3.

Karimi A, Fakhroueian Z, Bahramian A, Pour Khiabani N, Babaee Darabad J, Azin R, et al. Wettability alteration in carbonates using zirconium oxide nanofluids: EOR implications. Energy Fuels. 2012;26(2):1028-36. https://doi.org/10.1021/ef201475u.

Kumar S, Panigrahi P, Saw RK, Mandal A. Interfacial interaction of cationic surfactants and its effect on wettability alteration of oilwet carbonate rock. Energy Fuels. 2016;30(4):2846-57. https:// doi.org/10.1021/acs.energyfuels.6b00152.

Lin SY, Lin YY, Chen EM, Hsu CT, Kwan CC. A study of the equilibrium surface tension and the critical micelle concentration of mixed surfactant solutions. Langmuir. 1999;15(13):4370-6. https://doi.org/10.1021/la981149fCCC.

Maltesh C, Somasundaran P. Binding of sodium dodecyl sulfate to polyethylene oxide at the silica-water interface. Colloid Interface Sci. 1992;153(1):298-301. https://doi.org/10.1016/ 0021-9797(92)90322-D.

Mansur CR, Lucas EF, Pacheco CR, González G. Interação Tensoativo/Hidrótropo Em Sistemas Aquosos, Utilizando Ressonância Magnética Nuclear De 1H E13c. Quim Nova. 2001;24(1):47-54.

Moroi Y, Akisada H, Saito M, Matuura R. Interaction between ionic surfactants and polyethylene oxide in relation to mixed micelle formation in aqueous solution. Colloid Interface Sci. 1977;61(2):233-8. https://doi.org/10.1016/0021-9797(77)90386-1.

Müller AJ, Garcés Y, Torres M, Scharifker B, Sáez AE. Interactions between high-molecular-weight poly (ethylene oxide) and sodium dodecyl sulfate. Aqueous Polym-Cosolute Syst. Berlin: Springer; 2003. p. 73-81. https://doi.org/10.1007/b10527.

Nazari Moghaddam R, Bahramian A, Fakhroueian Z, Karimi A, Arya S. Comparative study of using nanoparticles for enhanced oil recovery: wettability alteration of carbonate rocks. Energy Fuels. 2015;29(4):2111-9. https://doi.org/10.1021/ef5024719.

Olajire AA. Review of ASP EOR (alkaline surfactant polymer enhanced oil recovery) technology in the petroleum industry: prospects and challenges. Energy. 2014;77(Supplement C):963-82. https://doi.org/10.1016/j.energy.2014.09.005.

Osterloh W, Jante Jr M. Surfactant-polymer flooding with anionic PO/ EO surfactant microemulsions containing polyethylene glycol additives. In: SPE/DOE enhanced oil recovery symposium, April 22-24, Tulsa, Oklahoma; 1992. https://doi.org/10.2118/24151MS.

Penfold J, Thomas RK, Taylor DJF. Polyelectrolyte/surfactant mixtures at the air-solution interface. Curr Opin Colloid Interface Sci. 2006;11(6):337-44. https://doi.org/10.1016/j. cocis.2006.08.003.

Pillai P, Kumar A, Mandal A. Mechanistic studies of enhanced oil recovery by imidazolium-based ionic liquids as novel surfactants. Ind Eng Chem. 2018;63:262-74. https://doi.org/10.1016/j. jiec.2018.02.024.

Purcell IP, Lu JR, Thomas RK, Howe AM, Penfold J. Adsorption of sodium dodecyl sulfate at the surface of aqueous solutions of poly(vinylpyrrolidone) studied by neutron reflection. Langmuir. 1998;14(7):1637-45. https://doi.org/10.1021/la971161s.

Raffa P, Broekhuis AA, Picchioni F. Amphiphilic copolymers based on PEG-acrylate as surface active water viscosifiers: towards new potential systems for enhanced oil recovery. Appl Polym Sci. 2016;133(42):44100. https://doi.org/10.1002/app.44100.

Saeki S, Kuwahara N, Nakata M, Kaneko M. Upper and lower critical solution temperatures in poly (ethylene glycol) solutions. Polymer. 1976;17(8):685-9. https://doi.org/10.1016/00323861(76)90208-1.

Salehi M. Enhancing the spontaneous imbibition process in naturally fractured reservoirs through wettability alteration using surfactants: mechanistic study and feasibility of using biosurfactants produced from agriculture waste streams. Ph.D. dissertation. University of Kansas. 2009.

Shirahama K. The binding equilibrium of sodium dodecyl sulfate to poly (ethylene oxide) in $0.1 \mathrm{M}$ sodium chloride solution at $30 \mathrm{C}$. Colloid Polym Sci. 1974;252(11):978-81.

Standnes DC, Austad T. Wettability alteration in chalk: 2. Mechanism for wettability alteration from oil-wet to water-wet using surfactants. Pet Sci Eng. 2000;28(3):123-43. https://doi.org/10. 1016/S0920-4105(00)00084-X.

Standnes DC, Austad T. Wettability alteration in carbonates: interaction between cationic surfactant and carboxylates as a key factor in wettability alteration from oil-wet to water-wet conditions. Colloids Surf A. 2003;216(1):243-59. https://doi. org/10.1016/S0927-7757(02)00580-0.

Torres MF, Müller AJ, Szidarovszky MA, Sáez AE. Shear and extensional rheology of solutions of mixtures of poly (ethylene oxide) and anionic surfactants in ionic environments. Colloid Interface Sci. 2008;326(1):254-60. https://doi.org/10.1016/j.jcis. 2008.07.032.

Umlong I, Ismail K. Micellization behaviour of sodium dodecyl sulfate in different electrolyte media. Colloids Surf A. 2007;299(1):8-14. https://doi.org/10.1016/j.colsurfa.2006.11. 010.

Zhang DL, Liu S, Puerto M, Miller CA, Hirasaki GJ. Wettability alteration and spontaneous imbibition in oil-wet carbonate formations. Pet Sci Eng. 2006;52(1):213-26. https://doi.org/10. 1016/j.petrol.2006.03.009. 